\title{
IMPLEMENTASI PENDISTRIBUSIAN ZAKAT FITRAH DI DESA KUTA TINGGI ACEH
}

\begin{abstract}
Khairuddin
Sekolah Tinggi Agama Islam Syekh Abdur Rauf e-mail: khairuddinazka15@gmail.com

\begin{tabular}{|l|l|l|}
\hline Submit: 19-06-2020 & Direvisi: 30-07-2020, & Dipublish: 18-12-2020
\end{tabular}

$25,31-08-2020$

Abstract: Zakat Fitrah is issued during the month of Ramadan. Every Muslim must release $2.8 \mathrm{~kg}$ of rice, both children and adults. The purpose of giving zakat is to clean the soul of murakki, in addition, to ease the burden on the poor so as to cause compassion among humans. Through this research can find out how the implementation of the distribution of Zakat Fitrah in Kuta Tinggi village and how the Islamic legal review of the distribution of Zakat Fitrah in Kuta Tinggi Village. This study uses qualitative descriptive. The results of the study obtained the distribution of Zakat Fitrah in Kuta Tinggi village one day before the feast day and given to four asnaf, namely the general public, amil, Islamic boarding school children and mosques. Reviewing Islamic law, giving alms to all people and mosques does not have a foundation because those who are entitled to get Zakat Fitrah have been determined by Allah in al-Qur'Aan surah Al-Taubah verse 60 .
\end{abstract}

Kata kunci: Hukum Islam, Implentasi, Pendistribusian, Zakat Fitrah.

\section{PENDAHULUAN}

Zakât fitrah merupakan zakat jiwa yang harus diberikan kepada orangorang yang berhak menerimanya. (Ayyub, 2004: 353) Kewajiban Zakat Fitrah merupakan kewajiban bagi setiap umat muslim, (Ibnu Rusyd, 2007: 622) sekalipun belum dewasa baik laki-laki maupun perempuan, dan tidak ada kewajiban zakat fitrah bagi orang kafir. (M. Ali As'ad: 1979: 2)

Zakat Fitrah termasuk kategori ibadah wajib sebagaimana shalat dan puasa di bulan Ramadhan yang telah ditetapkan tata caranya secara rinci berdasarkan al-Qur'an dan Hadis. Di sisi lain, Zakat Fitrah merupakan amal sosial kemasyarakatan dan kemanusiaan yang dapat berkembang sesuai dengan perkembangan umat Islam. (Khoiriyah, 2016) Zakat Fitrah wajib dikeluarkan pada setiap akhir bulan Ramadhan yaitu menjelang hari raya Idul Fitri. (Muhammad Daud Ali, 1988: 49) Diperbolehkan mengeluarkannya dari awal Ramadhan sampai hari terakhir bulan Ramadhan. Namun, waktu yang lebih baik yaitu dibayar setelah shalat subuh sebelum pergi shalat hari raya. (Rasjid, 2013: 209) Zakat Fitrah disyari'atkan pada tahun ke 2 hijriah di Madinah, namun dalam pembahasan zakat telah diuraikan di ayat makiyyah. (Kalimah, 2020: 16) Tujuan utama Zakat Fitrah untuk membersihkan jiwa orang yang berpuasa dari ucapan kotor dan perbuatan yang tidak berguna selama bulan Ramadhan serta untuk memberi 
makan kepada orang miskin dan mencukupkan mereka dari kebutuhan dan tidak meminta-minta pada hari raya. (Arlinta, 2020: 5) Dalil wajib membayar Zakat Fitrah adalah firman Allah SWT Dalam surah al-A'la ayat 14 dan 15 yaitu:

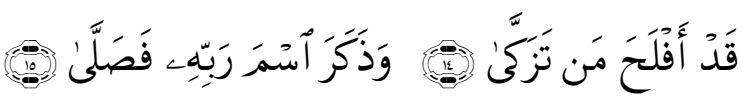

"Sesungguhnya beruntunglah orang yang membersihkan diri (dengan beriman), dan Dia ingat nama Tuhannya, lalu Dia sembahyang". (QS. al-A'la [87]: 14-15)

Selanjutnya hadis diriwayatkan oleh Bukhari yang berbunyi sebagai berikut:

عن إبن عمر رضى الله عنهما أن رسول الله صلى الله عليه

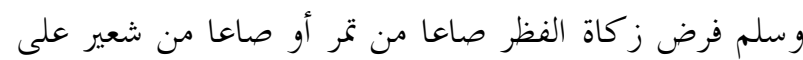

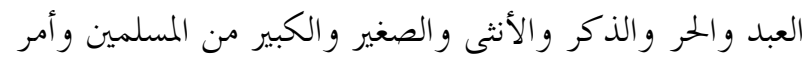
هـا أن تؤدى قبل خروج الناس الى الصلاة عيد الفطري ( رواه البخاري)

"Dari Ibnu Umar r.a, ia berkata: Rasulullah Saw, mewajibkan Zakat Fitrah sebanyak satu shaa' (satu gantang) kurma atau satu shaa' (gantang) gandum kepada orang-orang Islam, baik merdeka ataupun hamba, laki-laki ataupun perempuan, anak kecil ataupun oran dewasa. Rasulullah Saw, memerintahkan agar Zakat Fitrah dilakukan sebelum orang keluar untuk mendirikan salat hari raya".(HR. Bukhari) (Al-Bukhâri, 1992: 466)

Setelah harta diserahkan kepada amil zakat, maka pihak amil akan menyalurkannya kepada 8 golongan (mustahik), sejalan dengan firman Allah dalam at-Taubah ayat 60. Menurut Sayyid Sabiq mustahik Zakat Fitrah sama dengan mustahik zakat mal, artinya Zakat Fitrah hanya dibagikan kepada mustahik yang delapan. (Sabiq, 2005: 200)
Pembayaran Zakat Fitrah di Desa Kuta Tinggi Kecamatan Simpang Kanan setiap tahunnya terlaksana dengan baik. Tidak ada unsur paksaan, kesadaran masyarakat sangat tinggi sehingga semua masyarakat tersebut membayar Zakat Fitrahnya. Setelah Zakat Fitrah sudah terkumpul, maka beras sebagai Zakat Fitrah tersebut dijadikan satu, selanjutnya akan dimasukkan ke tempat beras untuk dibagikan kepada orang yang berhak.

Selanjutnya, Zakat Fitrah tersebut akan didistribusikan pada satu hari sebelum hari raya idul fitri kepada mustahik. Adapun orang yang berhak menerima Zakat Fitrah hanya empat asnaf saja yakni masyarakat yang menyerahkan Zakat Fitrah, fi sabîlillâh, amil dan masjid. Pembagian Zakat Fitrah kepada empat golongan tersebut sudah lama dipraktikkan oleh masyarakat Kuta Tinggi.

Seharusnya masyarakat Kuta Tinggi membagikan Zakat Fitrah sesuai dengan aturan agama Islam. Akan tetapi fakta di lapangan jauh dari kenyataan. Oleh karena itu, peneliti merasa sangat penting membahas lebih lanjut terkait bagaimana implementasi pendistribusian Zakat Fitrah di desa Kuta Tinggi Aceh

\section{METODE PENELITIAN}

Penelitian yang digunakan adalah sosio-legal. (Soerjono Soekanto, 2006: 51). Fokus penelitian ini mengenai bagaimana implementasi pendistri-busian Zakat Fitrah di desa Kuta Tinggi Aceh. Adapun lokasi penelitiannya di desa Kuta Tinggi Kecamatan Simpang Kanan Kabupaten Aceh Singkil Provinsi Aceh, dimulai pada tanggal 10 April sampai 30 Mei 2020.

Sumber data yang dibutuhkan yaitu sumber data primer yakni dikumpulkan 


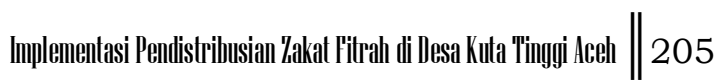

dari lapangan seperti hasil wawancara masyarakat Kuta Tinggi, wawancara dilakukan kepada bapak sekdes, imam, khatib, bilal, marbot masjid dan 25 kepala keluarga di desa Kuta Tingi terkait implementasi pendistribusian Zakat Fitrah, di sisi lain penulis juga menggunakan data sekunder yakni data yang diperoleh berupa dokumentasi dari masyarakat Kuta Tinggi yang ada kaitannya dengan penelitian ini.

Metode pengumpulan data yang digunakan adalah pengamatan langsung, dan wawancara yang mendalam. Observasi dilakukan dengan melihat proses pendistribusian zakat fitrah di Desa Kuta Tinggi, kemudian dilakukan wawancara yang mendalam kepada amil dan mustahiq zakat fitrah. Setelah itu, diambil sumber-sumber yang relevan yang dapat memberikan informasi yang valid.

\section{ZAKAT FITRAH DALAM HUKUM ISLAM}

\section{Definisi Zakat Fitrah}

Kata zakat fitrah sudah tidak asing lagi bagi umat Islam (Ainil, Layali, 2020: 57) yang secara bahasa berasal dari kata "زكى" yang masdarnya

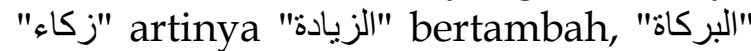
(keberkahan), "النماء" "(pertumbuhan dan perkembangan), "الطهرة" (kesucian) dan "الصلاحح (kebersihan) (Al-Manzhuri, 1997: 358) Sedangkan Zakat Fitrah secara istilah ialah zakat yang wajib bagi setiap kaum muslimin, laki-laki ataupun perempuan, besar ataupun kecil, merdeka ataupun budak yang memiliki kelebihan makan bagi diri dan keluarganya pada tanggal 1 Syawal. (Maghfiroh, 2007: 42)

Menurut Ali Hasan, Zakat Fitrah secara istilah adalah harta yang disisihkan di bulan ramadhan oleh seorang muslim atau badan yang dimiliki oleh orang muslim sesuai dengan ketentuan agama untuk diberikan kepada orang yang berhak menerimanya. (Hasan, 2008: 131) Menurut Wahbah az-Zuhaili, Zakat Fitrah secara istilah adalah sesuatu hak Allah SWT, yang dikeluarkan oleh seseorang kepada fakir miskin yang diharapkan bisa mendapatkan berkah, dan memenuhi kebutuhan mereka dan memupuk jiwa dengan kebaikan. (Zuhaili, 2010: 433) Menurut Sayyid Sabiq, Zakat Fitrah secara istilah adalah zakat yang diwajibkan karena berbuka dari Ramadhan (maksudnya: berakhirnya Ramadhan). Dia wajib bagi setiap pribadi umat Islam, anak-anak atau dewasa, laki-laki atau perempuan, merdeka atau budak, yang memiliki kelebihan satu sha' makanan bagi dirinya dan keluarganya satu hari satu malam. (Sabiq, 2006: 412) Menurut Yusuf Qardhawi berpendapat bahwa, Zakat Fitrah secara istilah adalah suatu kewajiban bagi kaum muslimin untuk mengeluarkan sejumlah harta tertentu disebabkan kita berbuka puasa. (Qardhawi, 2007: 920)

\section{Jenis dan Takaran Zakat Fitrah}

Zakat Fitrah yang hendak dikeluarkan berdasarkan makanan pokok setempat yang biasa muzakki konsumsi dalam kehidupan sehari-hari, jika muzakki tergolong kaya dan memakan beras yang level lebih tinggi maka ia 
wajib mengeluarkan zakat dari beras yang biasa mereka makan, jika seseorang tersebut termasuk keluarga sederhana dan memakan beras yang biasa maka zakat yang ia keluarkan juga dari yang biasa ia makan. Dengan demikian orang yang memakan beras merek ramos misalnya, maka tidak boleh mengeluarkan zakatnya dengan beras merek bulog.

Terkait dengan takaran Zakat Fitrah, menurut Imam Malik, Imam Syâfi'i, Imam Ahmad dan para ulama lain sepakat bahwa Zakat Fitrah ditunaikan sebesar satu shấ(setara dengan 2,8 kg) kurma, gandum, beras atau makanan lain yang menjadi makanan pokok di negeri tersebut. Sedangkan menurut Imam Hanafi membolehkan membayar Zakat Fitrah dengan uang senilai bahan makanan pokok setempat. Namun, ukuran satu sha" menurut pandangan Imam Hanafi lebih tinggi dari pada pendapat para ulama yang lain, yakni 3,8 Kg. (Mughniyah, 1994: 252)

\section{Pendistribusian Zakat Fitrah}

Terhadap delapan golongan yang berhak menerima zakat ditentukan oleh Allah SWT sendiri yang disebutkan dalam ayat suci al-Qur'an surat atTaubah ayat 60 sebagai berikut:

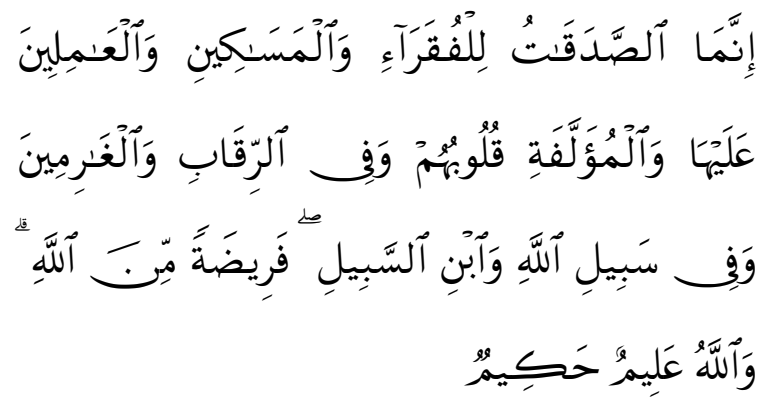

"Sesungguhnya zakat itu, hanyalah untuk orang fakir, miskin, pengurus zakat, para muallaf yang dibujuk hatinya, budak, orang-orang yang berhutang, untuk jalan Allah dan untuk mereka yuang sedang dalam perjalanan, sebagai suatu ketetapan yang diwajibkan Allah, dan Allah Maha mengetahui lagi Maha Bijaksana. (QS. at- Taubah [9]: 60)

Berdasarkan ayat di atas, sudah jelas bahwa orang yang berhak menerima zakat ada delapan golongan yang dijelaskan secara terperinci sebagai berikut:

a. Fakir

Fakir ialah orang melarat yang tidak mempunyai harta benda, tenaga dalam memenuhi kebutuhan pokoknya. (Basyir, 2002: 240)

b. Miskin

Orang miskin ialah orang yang memiliki pekerjaan tetapi penghasilannya tidak bisa memenuhi kebutuhannya sehari-hari. (Zuhaili, 1997:281) Mereka kebalikan orangorang kaya, yaitu orang yang mampu memenuhi apa yang diperlukannya. Lebih jauh, seseorang dikatakan kaya jika ia memiliki harta yang telah mencapai nisab, yaitu sejumlah harta yang menjadi kebutuhan dasar baginya dan sanak keluarganya berupa keperluan makan, minum, pakaian, rumah, kendaraan dan sebagainya. Jadi, orang yang tidak memiliki semua itu dikatakan sebagai miskîn dan berhak menerima zakat.

c. Amil Zakat

Amil Zakat adalah orang yang ditunjuk pemimpin umat Islam atau gubernur untuk mengumpulkan zakat. kelompok amil zakat di antaranya adalah petugas dan pengatur administrasi zakat. Meng- 
ambil bagian dalam pengaturan zakat mendapat imbalan. Petugas pun harus dibayar, baik orang kaya maupun orang miskin.

d. Muallaf

Muallaf ialah orang yang baru memeluk Islam yang imannya masih lemah agar lebih teguh dan memegang erat agama Islam. (AshShiddiqy, 2006: 179)

e. Budak

Seorang budak yang ingin membebaskan dirinya dari perbudakan wajib diberi zakat agar ia bisa membayar uang kepada pembebasan yang diperlukan kepada tuannya. Sekarang, karena perbudakan sudah tidak ada, maka kategori ini berlaku bagi orang yang terpidana yang tidak mampu membayar denda yang dibebankan kepadanya. Mereka dapat dibantu dengan zakat agar terjamin kebebasannya.

f. Ghârimîn (Orang yang Terbebani Hutang)

Orang yang terbebani hutang dan tidak bisa membayarnya berhak menerima zakat agar bisa melunasinya. Orang yang berhutang terbagi ke dalam empat bagian, yaitu:

1).Orang yang menanggung hutang orang lain karena kekeliruan sehingga menjadi kewajibannya;

2).Orang yang salah mengatur keuangan;

3).Orang yang bertanggung jawab untuk melunasi utang;

4). Orang yang terlibat perbuatan dosa dan kemudian bertobat. Semua kategori yang tercantum di atas boleh menerima zakat agar hutangnya terlunasi.

\section{g. Fisabîlillâh}

Sabîlillâh merupakan istilah umum yang digunakan untuk seluruh jalan yang menuju kepada perbuatan baik. Secara khusus berarti memberi pertolongan dalam jihad (perjuangan) agar Islam berjaya di dunia. (Ash-Shiddiqy, 2006: 181)

\section{h. Ibnu Sabîl}

Ibnu Sabîl adalah orang yang melintas dari satu daerah ke daerah lain. Jumhur ulama sepakat bahwa mereka hendaknya diberi zakat dalam jumlah yang cukup untuk menjamin mereka pulang walaupun ia termasuk orang kaya di negerinya. (Qardhawi, 2007: 645)

\section{Tujuan Dan Hikmah Zakat Fitrah}

Sebagai pokok ajaran agama atau ibadah, zakat mengandung tujuan dan hikmah tertentu baik bagi orang yang berzakat (muzaki) ataupun bagi penerimanya (mustahiq), sebagaimana arti zakat yang berarti suci Zakat Fitrah berfungsi sebagai mensucikan orang yang telah melakukan kesalahan seperti perbuatan dan perkataan yang kosong dan keji saat melakukan ibadah puasa. (Sabiq, 2006: 413)

Tujuan mengeluarkan Zakat Fitrah yakni:

1) Menarik rasa simpati/cinta

2) Membantu, mengurangi, dan mengangkat kaum fakir miskin dari 
kesulitan hidup dan penderitaan mereka.

3) Membantu memecahkan masalah yang dihadapi oleh ghârimîn, ibn sabîl, dan para mustahiq lainnya.

4) Membina dan merentangkan tali solidaritas (persaudaraan) sesama umat manusia.

5) Mengimbangi ideologi kapitalisme dan komunisme.

6) Menghilangkan sifat bakhil dari pemilik kekayaan dan penguasa modal.

7) Menghindarkan penumpukan kekayaan perorangan yang dikumpulkan di atas penderitaan orang lain.

8) Mencegah semakin dalamnya jurang pemisah antara si kaya dan si miskin yang dapat menimbulkan kecemburuan sosial, yang pada akhirnya dapat memicu timbulnya kejahatan.

9) Mengembangkan tanggung jawab perorangan terhadap kepentingan masyarakat.

10)Mendidik kedisiplinan dan loyalitas seorang muslim untuk menjalankan kewajibannya dan menyerahkan hak orang lain. (Departemen Agama, 2002: 183)

Selain beberapa tujuan seperti tersebut di atas, zakat juga mengandung hikmah dan keutamaankeutamaan tertentu, yaitu:

1) Membersihkan dan mensucikan diri sebagaimana terkandung dalam ayat-ayat sebagai berikut: surah atTaubah ayat 103 :

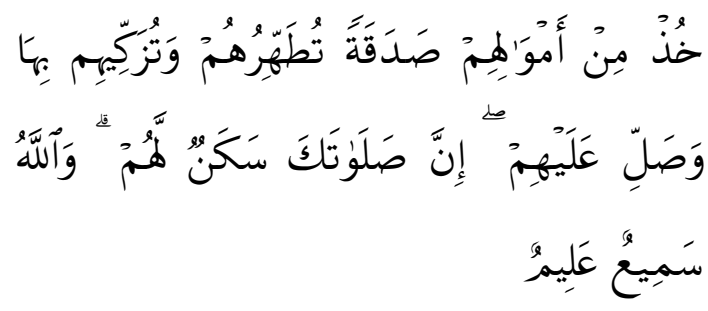

"Ambillah zakat dari sebagian harta mereka, dengan zakat itu kamu membersihkan dan mensucikan mereka dan mendoalah untuk mereka. Sesungguhnya doa kamu itu (menjadi) ketenteraman jiwa bagi mereka. dan Allah Maha mendengar lagi Maha mengetahui". (QS. at- Taubah [9]: 103)

2) Mensyukuri karunia Allah Swt. menumbuhsuburkan harta dan pahala serta membersihkan diri dari sifat-sifat kikir dan loba, dengki, iri, serta dosa;

3) Melindungi masyarakat dari bahaya kemiskinan dan akibat kemelaratan;

4) Mewujudkan rasa solidaritas dan kasih sayang antara sesama manusia;

5) Manifestasi kegotongroyongan dan tolong menolong dalam kebaikan dan takwa;

6) Mengurangi kefakirmiskinan yang merupakan masalah sosial;

7) Membina dan mengembangkan stabilitas sosial;

8) Salah satu jalan mewujudkan keadilan sosial;

9) Zakat menghilangkan perbedaanperbedaan sosial yang tajam, dapat menjadi alat untuk menghilangkan jurang pemisah antara orang-orang kaya dan orangorang miskin. (Razak, 1996: 193) 


\section{IMPLEMENTASI PENDISTRIBUSIAN ZAKAT FITRAH MASYARAKAT KUTA TINGGI}

Menurut jumhur fuqaha, Zakat Fitrah wajib sebab tenggelamnya matahari pada malam hari raya ldul Fitri, yaitu malam pertama hari Idul Fitri. Karena, Zakat Fitrah di dalam keterangan hadishadis yang telah disebutkan, disandarkan kepada fithr (berbuka) dari puasa Ramadhan. Maka, dimulai wajib menunaikannya ketika tenggelamnya matahari, karena penyandaran tersebut berfungsi untuk pengkhususan. Berbuka pertama yang terjadi di seluruh bulan Ramadhan dan tidak ada kewajiban puasa setelahnya adalah setelah tenggelamnya matahari pada malam Idul Fitri dan selesainya puasa dengan tenggelamnya matahari. (Mughniyah, 1994: 255)

Sebelum pembayaran Zakat Fitrah di desa Kuta Tinggi bisanya diumumkan pada hari jumat bulan Ramadhan oleh pihak pengurus masjid berapa Zakat Fitrah perindividu yang wajib dikeluarkan, karena amalan ini hanyalah setahun sekali, dan dikhawatirkan masyarakat ada yang lupa atau ada yang tidak mengetahui sama sekali.

Pembayaran Zakat Fitrah dimulainya pada malam tanggal 27 Ramadhan sampai malam 1 syawal. Pembayaran ini ditunaikan dengan menggunakan makanan pokok setempat yakni beras, takaran yang dikeluarkan 2, 8 $\mathrm{kg}$ beras, atau sepuluh aco (Aco adalah takaran beras di desa Kuta Tinggi, yang terbuat dari kaleng susu).

Zakat Fitrah diberikan kepada amil/ imam masjid setelah selesai pelaksanaan shalat jamaah terawih dan witir, bagi yang menyerahkan zakatnya, maka pihak amil mencatat nama muzakki, agar tahu, siapa saja yang telah mengeluarkan Zakat Fitrah, dan agar lebih mudah dalam hal membagikannya karena telah menulis nama-nama yang menyerahkan Zakat Fitrahnya. Sehingga disaat membagikan kepada mustahik akan jauh lebih mudah.

Penyaluran zakat kepada golongan yang berhak yang sesuai menurut ketentuan syariat yaitu fakir, miskin, amil, mu'allaf, budak, ghârimîn, fi sabîlillâh dan ibnu al-sabîl, sebagaimana yang tercantum dalam surah al-Taubah ayat 60 . Penyaluran Zakat Fitrah memiliki tujuan yakni untuk meningkatkan kesejahteraan masyarakat di bidang perekonomian sehingga dapat minimalisir kemiskinan masyarakat. (Mursyidi, 2003: 169)

Praktik pendistribusian Zakat Fitrah di desa Kuta Tinggi yaitu satu hari sebelum hari raya, misalnya hari raya jatuh pada hari minggu, maka Zakat Fitrah akan didistribusikan kepada mustahiknya pada hari sabtu setelah shalat juhur.

Adapun masyarakat yang mengeluarkan Zakat Fitrah setelah pendistribusian zakat, maka pihak amil tetap menerimanya, dan amil tidak membagikannya kepada masyarakat miskin dari rumah kerumah, akan tetapi dimasukkan kebagian masjid (ghârimîn)

Penyaluran Zakat Fitrah di desa Kuta Tinggi Kecamatan Simpang Kanan Aceh diberikan kepada 4 asnaf yaitu:

\section{Masyarakat Umum}

Adapun pengertian masyarakat umum ialah seluruh masyarakat yang telah mengeluarkan Zakat Fitrahnya, maka ia tergolong sebagai mustahik, 
walaupun ia tergolong sebagai orang yang kaya/mampu di desa tersebut.

Bagian masyarakat umum dikatagorikan menjadi dua bagian yakni masyarakat umum yang masih memiliki suami, dan masyarakat yang tidak memiliki suami, yang mereka kenal dengan sebutan mekhanda (janda).

Pendistribusian zakat kepada masyarakat umum golongan pertama, baik orang kaya maupun miskin sama bagiannya. Ini terjadi pada Ramadhan $1441 \mathrm{H}$, bagian orang kaya dan miskin, masing-masing diberikan satu bambu tiga muk. Sehingga hal ini menimbulkan kecemburuan sosial karena kesamaan bagian antara yang mampu dengan yang tidak mampu, padahal prioritas utama Zakat Fitrah adalah fakir dan miskin. Sedangkan bagian mekhanda lebih banyak dibandingkan dengan masyarakat umum golongan pertama. Pada tahun 2020 mereka mendapatkan tiga bambu masingmasing orang mekhanda.

Pendistribusian Zakat Fitrah kepada seluruh mekhanda/janda yang ada di desa Kiya Tinggi tanpa terkecuali, dari sepuluh janda yang di data ada 2 orang yang tergolong mampu, memiliki rumah beton dan sawit yang luas. Namun, atas nama janda maka mereka tetap dapat bagian walaupun mereka tergolong janda yang mampu.

Hal ini sudah dipraktikkan dari dulunya sampai sekarang, perbuatan yang terus menerus itu menjadi hukum bagi mereka. Jika melihat praktik pendistribusian Zakat Fitrah kepada seluruh masyarakat Kuta Tinggi maka dalam hal ini mengenai pendistribusian tersebut belum sesuai dengan syariat.
Begitu juga yusuf Qardhawi mengatakan orang kaya tidak boleh diberi bagian Zakat Fitrah, kecuali sebagai amil atau tentara perang. Pemberian zakat kepada orang kaya akan merusak tujuan diwajibkannya zakat yaitu memberikan kecukupan orang fakir dan miskin, sejalan dengan hadis "tidak ada hak zakat untuk orang kaya, (HR. Nasa'i) (Qardhawi, 2007: 674)

\section{FiSabîlillâh}

Para ulama berselisih pendapat tentang yang dimaksud fi Sabîlillâh. Menurut jumhur ulama yang dimaksud dengan sabîlillâh ialah berperang, dan bagiannya diberikan kepada tentara sukarelawan yang tidak mendapat upah dari pemerintah, mereka berhak mendapatkan Zakat Fitrah walaupun termasuk golongan orang kaya. (Sabiq, 2005: 574) Di sisi lain, fisabîlillâh juga diartikan sebagai perbuatan yang diridhai Allah dan mencakup kepada seluruh kepetingan orang banyak seperti pembangunan masjid, madrasah, rumah sakit dan lain sebagainya. (Uwaidah, 2008: 311)

Persepsi masyarakat Kuta Tinggi memahami makna fisabîlillâh sedikit berbeda, mereka memahaminya sebagai anak pesantren karena mereka dikatagorikan sebagai pejuang agama. Oleh karena itu, setiap anak di masyarakat Kuta Tinggi yang sekolah di pondok pesantren baik salafi maupun modern kelas 1 maupun kelas 7 berhak mendapatkan Zakat Fitrah.

Ada hal yang menarik perhatian penulis ketika menanyakan bagian $f i$ sabîlillâh. Bagian fisabîlillâh lebih banyak ketimbang bagian orang miskin, padahal tujuan utama Zakat Fitrah 
kepada orang miskin. Pada tahun 2020 fisabîlillâh di desa Kuta Tinggi ada 8 orang, dan bagian yang diterima dua bambu tiga muk sedangkan orang miskin hanya mendapat satu bambu tiga muk.

Pendistribusian Zakat Fitrah kepada anak pesantren mengandung kemashlahatan seperti termotivasinya orang tua di desa Kuta Tinggi dalam menyekolahkan anaknya ke pendidikan pesantren/dayah, karena adanya kepedulian agama terhadap anak-anak yang menuntut ilmu agama.

\section{Amil}

Pembentukan badan amil zakat merupakan wujud nyata perhatian pemerintah terhadap kehidupan umat Islam, sehingga diperlukan sebuah mekanisme yang mampu mengalirkan kekayaan yang dimiliki oleh kelompok masyarakat mampu (the have) kepada kelompok masyarakat yang tidak mampu (the hevenot). (Hartatik, 2015: 31)

Pada tahun 2020/1441 H, jumlah amil yang mengurus zakat ada enam orang, termasuk bagian KUA Simpang Kanan. Amil ini memiliki jatah Zakat Fitrah karena kinerjanya. Namun, dalam membagikan Zakat Fitrah, bagian amil yang paling banyak ketimbang bagian orang miskin yang ada di desa Kuta Tinggi. Faktornya, amil tergolong sebagai orang miskin dan juga sebagai amil, maka wajar bagian amil lebih banyak dari pada golongan lainnya.

Jika dirincikan, setiap amil mendapatkan $20 \mathrm{bambu}$, praktik seperti ini sudah diterapkan sejak lama, bukan di desa ini saja, akan tetapi berlaku juga desa tetangga seperti desa Lae Nipe, Pakiraman dan Pertabas.

\section{Masjid}

Masyarakat Kuta Tinggi, berasumsi masjid merupakan salah satu golongan yang berhak menerima zakat, masjid ini digolongkan sebagai ghârimîn (orang yang berhutang), masjid al-Hidayah Kuta Tinggi ini masih dalam proses pembangunan, maka oleh karenanya banyak hutang sana-sini, atas nama masjid, sehingga masjid bisa dikatagorikan sebagai ghârimîn. Bukan hanya berada di desa Kuta Tinggi saja, melainkan ada beberapa di desa di wilayah Kecamatan Gunung Meriah yang mempraktikkan masjid atau mushalla sebagai mustahik zakat.

Masjid mendapat bagian Zakat Fitrah pada tahun 2020 sebanyak 10 belek. Belek adalah sebutan banyaknya beras yang telah sampai 10 bambu. Jika dirincikan, satu belek itu sama dengan 10 bambu beras, jadi 20 belek sama halnya 100 bambu beras. Bagian masjid tersebut dijual dan uangnya dibelikan kepada sesuatu yang bermanfaat bagi masjid. Menurut keterangan Asir salah satu Tokoh Agama Kuta Tinggi, hasil penjualan beras pada tahun 2020 seharga 1400.000 rupiah, selanjutnya masyarakat bermusyawarah terkait uang tersebut dan hasilnya mereka membeli sebuah kubah kecil dengan harga 1.300.000 rupiah.

Padahal seharusnya hasil Zakat Fitrah didistribusikan kepada golongan yang berhak menerimanya, terutama fakir dan miskin, bukan dibuat untuk 
kepentingan-kepentingan yang lain, yang dikhawatirkan pemahaman yang berhak menerima zakat semakin luas sehingga hilangnya pemahaman seseorang terhadap ayat tentang mustahik zakat.

Terkait tentang pendis-tribusian Zakat Fitrah kepada masjid masih polemik antara boleh dan tidak, begitu juga dengan pandangan masyarakat Kuta Tinggi, ada yang menyatakan boleh mengeluarkan Zakat Fitrah kepada masjid seperti yang dikatakan oleh Maksum. Berbeda dengan pandangan Syarmin, pem-berian Zakat Fitrah kepada masjid tidak memiliki keterangan, oleh karenanya, dana untuk masjid disalurkan kembali kepada golongan yang tidak mampu. Mustahiq zakat seharusnya dapat memiliki, sedangkan masjid tidak bisa memiliki.

Jika kita kembalikan persoalan mustahiq yang sejalan dengan AlQur'an maka tidak akan ditemukan Zakat Fitrah disalurkan kepada masjid. Jumhur ulama sepakat bahwa amil tidak boleh mengeluarkan zakat selain dari delapan golongan yang telah ditetapkan Allah SWT Seperti membuat jembatan, perbaikan jalan, membangun masjid. (Zuhaili, 1997: 875)

\section{KESIMPULAN}

Hukum pendistribusian zakat fitrah kepada 4 asnaf yang terdiri dari masyarakat umum, anak pesantren, masjid dan amil dalam pandangan hukum Islam dapat diambil kesimpulan yaitu:

1. Pendistribusian zakat fitrah kepada masyarakat umum yang sesuai kriteria seperti halnya fakir dan miskin, maka hal ini sejalan dengan firman Allah SWT Dalam surah al-Taubah ayat 60, akan tetapi sangat dilarang jika membagikan zakat fitrah kepada orang mampu.

2. Anak pesantren dijadikan sebagai penerima zakat, hal ini tidak ada larangan dikarenakan mereka juga merupakan penerima zakat dari golongan fisabîlillâh

3. Masjid, masuk katagori golongan ghârimîn (orang yang berhutang untuk kebaikan), padahal masjid tidak berhak mendapatkan zakat fitrah

4. Amil zakat, yakni orang yang bertugas mengumpulkan dan membagikan zakat. Sedangkan seperti bagian fakir, ibnu sabîl, muallaf dan budak tidak ditemukan di desa tersebut sehingga yang empat golongan ini tidak pernah mendapat bagian zakat.

\section{DAFTAR PUSTAKA}

Al-Bukhâri, A. M. bin I. (1992). Shahih Bukhâri (Jilid 1-2). Beirut: Darul Fikr.

Al-Manzhuri, A. F. J. (1997). Lisan al'Arabi. Beirut: Darul Fikr.

Arlinta, P.D. (2020). Telaah Kritis Praktik Pendistribusian Zakat Di Desa Ngadirojo Soko Ponogoro Tahun 2019. At-Tasyri' : Jurnal Hukum dan Ekonomi Syari'ah, 1(02).

As-'Ad, M.A. (1979). Terjemah Fathul Mu'in. (Jilid. 2,). Yogyakarta: Menara Kudus.

Ash-Shiddiqy, T.H. (2006). Pedoman Zakat. Semarang: Pustaka Rizki Putra.

Ayyub, S. H. (2004). Fikih Ibadah. Jakarta: Pustaka Al-Kautsar.

Basyir, A.A. (2002). Hukum Zakat. Jakarta: 
Majelis Pustaka Pimpinan Pusat Muhammadiyah.

Bambang Dwiloka, R. R. (2005). Teknik Menulis Karya Ilmiah. Jakarta: Rineka Cipta.

Departemen Agama. (2002). Pedoman Zakat 9 Seri. Jakarta: Proyek Pembinaan Zakat dan Wakaf.

Hartatik, E. (2015). Analisis Praktik Pendistribusian Zakat Produktif Pada Badan Amil Zakat Daerah (BAZDA) Kabupaten Magelang. Az Zarqa', 7(1).

Hasan, A. (2008). Infak Salah Satu Mengatasi Problema Sosial di Indonesia. Jakarta: Kencana Prenada Media Group.

Ibnu Rusyd. (2007). Bidayatul Mujtahid: Analisa Fiqih Para Mujtahid. Jakarta: Pustaka Amani.

Idayanti, R. (2018). Distribusi Zakat Fitrah pada Masyarakat miskin Kecamatan Tanete Riattang Barat. ILTIZAM (Journal Of Shariah Economic Research), 2(1).

Iqbal Hasan. (2002). Metodologi Penelitian dan Aplikasinya. Bogor: Ghalia Indonesia.

Kalimah, S. (2020). Pandangan Ulama Empat Mazhab dalam Memutuskan Upah Amil Zakat Guna Meningkatkan Optimalisasi Keprefesionalan Amil Zakat. Salimiya: Jurnal Studi Ilmu Keagamaan Islam, 1(01).

Khoiriyah, S. (2016). Tradisi Pendistribusian Zakat Fitrah Kepada Ustaz Di Desa Batonaong. Maliyah, 6(2).
Layali. A. (202). Pendistribusian Zakat Fitrah Persfektif Imam Syafi'i. Mabahits: Jurnal Hukum Keluarga Islam, 1(01).

Maghfiroh, M. (2007). Seri Tuntunan Praktis Ibadah. Yogyakarta: Insan Madani.

Mughniyah, M. J. (1994). Fiqih Lima Mazhab Ja'fari, Hanafi, Maliki, Syafii, dan Hanbali. Jakarta: Basrie Press.

Muhammad Daud Ali. (1988). Sistem Ekonomi Islam Zakat Dan Wakaf. Jakarta: UI Press.

Mursyidi. (2003). Akuntansi Zakat Kontemporer. Bandung: PT. Remaja Rosdakarya.

Mushthafa, M. (2019). Mustahiq Zakat Fitrah Dan Relevansinya Dengan Kewajiban Menunaikannya Bagi Setiap Muslim (Telaah Pendapat Imam Malik W. 178 H). JURIS (Jurnal Ilmiah Syariah), 18(1).

Qardhawi, Y. (2007). Fiqhuz Zakat, (terj. Salman Harun). Jakarta: Lintera Antar Nusa.

Rasjid, S. (2013). Fiqih Islam: Hukum Fiqih Islam. Bandung: Sinar Baru Algensindo.

Razak, N. (1996). Dinul Islam. Bandung: Al Ma'arif.

Sabiq, S. (2005). Panduan Zakat Menurut alQur'an dan as-Sunnah. Bandung: Ibnu Katsir.

Sabiq, S. (2006). Fiqhus Sunnah. terj. Hasanuddin (Jilid. 2, ). Jakarta: Pena Pundi Aksara.

Saleh, H. E. H. (2008). Kajian Figh Nabawi $\mathcal{E}$ Figh Kontemporer. Jakarta: Rajawali 
214 || Jur'nal Inmiah Sygari'ah, Volume 19, Nomor 2, Juli-Desember 2070?

Pres.

Soekanto, Soerjono. (2006). Pengantar Penelitian Hukum. Jakarta: UI Pres.

Uwaidah, S. K. M. (2008). Fiqih Wanita. Jakarta: Pustaka Al-Kausar.
Zuhaili, W. (2010). al-Fiqhu asy-Syafi'i alMuyassar. terj. Mohd Afifi. (cet. 1.). Jakarta: Rosydakarya.

(1997), al-Figh Islami Adillatuhu. terj. Agus Efendi. (cet. 1.). Bandung: Remaja Rosdakarya. 